REVIJA ZA ELEMENTARNO IZOBRAŽEVANJE JOURNAL OF ELEMNTARY EDUCATION

Vol. 11, No. 4, pp. 329-340, December 2018

\title{
PRIMERJEVA ŠPORTNIH DEJAVNOSTI UČENCEV IZ MARIBORA IN NOVEGA SADA
}

\author{
Jasmina JANČIČ ${ }^{1} \&$ JuRij PlaninšEC ${ }^{2}$ \\ ${ }^{1}$ Osnovna šola Sladki Vrh, Sladki Vrh, Slovenija \\ ${ }^{2}$ Univerza v Mariboru, Pedagoška fakulteta, Maribor, Slovenija
}

Potrjeno/Accepted

20. 11. 2018

Objavljeno/Published 20. 12. 2018

KORESPONDENČNI AVTOR/CORRESPONDING AUTHOR jurij.planinsec@um.si

Povzetek/Abstract Namen raziskave je bil ugotoviti, koliko in na kakšen način so športno dejavni učenci iz Maribora in Novega Sada ter ali obstaja razlika $\mathrm{v}$ športni dejavnosti učencev iz omenjenih mest. $\mathrm{V}$ raziskavo sta bila vključena 202 učenca 4., 5., 6. in 7. razredov osnovnih šol, in sicer 100 učencev iz Novega Sada ter 102 učenca iz Maribora; od tega je bilo 96 deklet in 106

Ključne besede: gibalna dejavnost, šolski šport, Slovenija, Srbija, učenci.

Keywords: Sport activity, school sport, Slovenia, Serbia, students.

UDK/UDC

796:373.3-

053.5(497.412:497.11Novi $\mathrm{Sad})$ fantov. Za zbiranje podatkov smo uporabili anketni vprašalnik, ki so ga učenci izpolnjevali v maternem jeziku. Dobljene podatke smo obdelali s programom SPSS 21, pri tem smo uporabili $\chi^{2}$-preizkus in t-preizkus. Rezultati kažejo, da obstajajo statistično pomembne razlike med učenci iz Maribora in učenci iz Novega Sada pri obiskovanju športnih interesnih dejavnosti v šoli, pri športnem udejstvovanju $\mathrm{z}$ družinskimi člani ter $\mathrm{v}$ neorganiziranih športnih dejavnostih. Pri obiskovanju organiziranih izvenšolskih športnih dejavnosti pa ni bilo statistično pomembne razlike. Sklenemo lahko, da so učenci iz Maribora v povprečju športno dejavnejši kot učenci iz Novega Sada.

Comparison of sports activities among students from Maribor and Novi Sad The main aim of the study was to determine the extent of physical activity among students from Maribor and Novi Sad, the nature of such activity and whether there is a difference in the physical activities of students from these cities. The study involved 100 students from Novi Sad and 102 students from Maribor, who attended the 4th, 5th, 6th and 7th grades of elementary schools, of which 96 were girls and 106 boys. In order to collect data, we used a survey questionnaire that students completed in their mother language. The data was processed with the SPSS 21 program, using the $\chi^{2}$-test and t-test. The results show that there are significant differences between students from Maribor and students from Novi Sad in attending physical activities at school, physical activities with the family and in unorganized physical activity. There was no significant difference in attendance at organized physical activities. We can conclude that students from Maribor are more physically active than are students from Novi Sad.

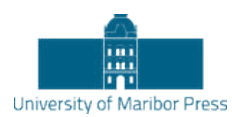




\section{Uvod}

Na eni strani je za današnji način življenja značilen vse bolj sedeči življenjski slog. $\mathrm{Na}$ drugi strani pa se zavedamo, da je eden najpomembnejših dejavnikov, ki nam zagotavlja kakovostno življenje, vsekakor gibalna dejavnost. Ta je izredno pomembna predvsem za mlade in njihov razvoj, saj ohranja primerno raven telesne pripravljenosti, krepi in varuje zdravje ter prispeva $\mathrm{k}$ oblikovanju takšnih navad in vedenjskih vzorcev, ki zagotavljajo vseživljenjsko gibalno aktivnost (Bouchard, Blair, Haskell, 2012). Otroštvo in mladostništvo sta pri pridobivanju teh navad izjemno pomembni obdobji, zato je treba pravočasno poskrbeti, da se bodo mladi na gibalno aktivnost navadili ter prevzeli dejaven in zdrav način življenja (Planinšec, Pišot, Fošnarič, 2006; Strong idr. 2005).

Vedenjski vzorci športnega udejstvovanja in gibanja, ki jih človek pridobi $\mathrm{v}$ otroštvu, se ohranijo skozi celo življenje in sooblikujejo temelje za aktivno in zdravo življenje. Premalo športne dejavnosti ali pa napačno oziroma pretirano izvajanje gibalnih aktivnosti lahko negativno vpliva na otrokov razvoj, predvsem pa se lahko upočasnijo gibalni, socialni in čustveni razvoj otroka (World Health Organization, 2013).

Gibalno dejavnost predstavljajo prostovoljna, zavestna gibanja, izvedena z namenom doseganja ciljev na področju športa, vadbe ali katerem drugem področju človekovega delovanja (Hoffman, 2013). Športna dejavnost je podkategorija gibalne dejavnosti in predstavlja načrtovano, strukturirano, ponavljajočo se dejavnost, katere cilj je izboljšati in ohranjati zdravje in razvoj gibalnih kompetenc (Word Health Organization, 2017). Sodobna priporočila navajajo, naj bodo otroci in mladostniki vsakodnevno gibalno aktivni vsaj eno uro ali več, pri čemer naj le-ta dosega zmerno do visoko intenzivnost, najmanj dvakrat tedensko pa naj bo aktivnost namenjena ohranjanju in izboljšanju moči ter gibljivosti (Landry, Driscoll, 2012).

Gibalna dejavnost je lahko tudi sredstvo, ki mladim omogoča neposredno vključevanje v okolje, $v$ katerem živijo, hkrati pa jim omogoča pridobivanje bogatih izkušenj in doživetij, zlasti v otroštvu. Odrasli so zgled in s svojim vedenjem vplivajo na oblikovanje zdravega življenjskega sloga otroka oziroma mladostnika (Pišot in Planinšec, 2005), to pa posledično vpliva na vedenje odraslih. Med najpomembnejšimi dejavniki, od katerih je odvisno vključevanje otrok in mladostnikov v gibalne dejavnosti, je okolje, v katerem prebivajo (McCormack idr. 2011; Panter idr. 2017). Pri tem je pomembno tako individualno, družbeno kot 
materialno oziroma grajeno okolje. Materialno okolje je torej eden od pomembnih dejavnikov športnega udejstvovanja, zato je treba vzpostaviti učinkovito in dostopno mrežo kakovostnih športnih objektov ter naravnih površin za šport. Dobro je treba izkoristiti tudi športne prostore $\mathrm{v}$ šolah, in sicer za potrebe mladih in tudi odraslih, predvsem izven pouka in šlskih delovnih dni. $\mathrm{Na}$ tak način je mogoče ustvariti povezave med športom $\mathrm{v}$ družini, šoli in društvih. Športnorekreacijski objekti morajo biti dostopni vsem skupinam prebivalstva. Urediti pa je treba tudi ustrezne varne poti do športnih površin. Celostni vidik športa in športne ozaveščenosti mora poudarjati urejenost naravnega prostora za športne namene (Nacionalni program športa v RS, 2014).

Vsekakor sodijo tudi športne površine med najpomembnejše dejavnike, od katerih je odvisna športna dejavnost otrok, zato morajo biti raznolike, zadostne po številu in dostopne (Norman idr.. 2010). Športne površsine v tehnično-arhitekturnem smislu pomenijo vse prostore in površine odprtega ali zaprtega stavbnega objekta, namenjenega za izvajanje določenih športnih dejavnosti (vadba, usposabljanje, tekmovanje, zabava). Śportni objekti so lahko zasnovani in zgrajeni kot večnamenski kompleksi z različnimi napravami ter prostori, kot so športne dvorane, stadioni, rekreacijski centri, šolske ustanove za telesno vzgojo in podobno (Anastasovski, 2014).

V mestni občini Maribor je po podatkih iz leta 2011 skupno 326 vadbenih površin, na katerih je možno izvajati različne športne programe. Gre za različne športne objekte oziroma igrišča, telovadnice, dvorane, steze, bazene, hipodrom, smučišča, strelišča, tekaška proge in dvorane za fitnes, s katerimi razpolaga Maribor, in so namenjeni za izvajanje rednih športnih programov, športni rekreaciji, preventivni ter korektivni zdravstveni vzgoji (Kosi, 2011). V Novem Sadu je veliko športnih objektov, ki omogočajo izvajanje različnih oblik športnih dejavnosti za vse starostne skupine, prevladujeta pa dva velika športna centra, to sta Športni in poslovni center Vojvodina - SPENS ter Športni center Sajmište. Omeniti je treba tudi nogometni stadion Karađorđe ter novosadsko plažo Štrand. V mestu je še mnogo športnih objektov, kot so Športni center Slana Bara, Stadion Derelinara, hipodrom ter drugi, po podatkih Pokrajinskega sekretariata za sport i omadinu je registriranih 451 športnih in rekreacijskih društev ter klubov (https://www.sio.vojvodina.gov.rs/index.php/en/).

Raziskav, v katerih bi primerjali športno dejavnost otrok v Sloveniji in Srbiji, praktično ni. Še najbližje temu področju sta dve raziskavi, v katerih so primerjali gibalne sposobnosti slovenskih ter srbskih otrok in mladostnikov. Pri tem so bili 
fantje iz Beograda $v$ vseh testih gibalnih sposobnosti, razen $v$ gibljivosti, boljši od vrstnikov iz Ljubljane. Po drugi strani pa so bila v vseh testih boljša dekleta iz Ljubljane. Ugotovitve so avtorji pojasnili s poznejšim zorenjem fantov iz Ljubljane in njegovim učinkom na razvoj gibalnih sposobnosti (Jurak idr., 2011). V drugi podobni raziskavi so ugotovili, da so bili slovenski fantje in slovenska dekleta $\mathrm{v}$ dveh testih gibalnih sposobnosti, skoku $\mathrm{v}$ daljino $\mathrm{z}$ mesta in vesi $\mathrm{v}$ zgibi boljši kot srbski vrstniki. Poleg tega so bile razlike med učenci obeh držav večje pri 9-letnikih kot pri 14-letnikih (Jurak idr., 2015). V obeh raziskavah ugotavljajo, da imajo slovenski in srbski učenci bolj razvite gibalne sposobnosti kot njihovi vrstniki iz drugih evropskih držav. Pri teh dveh raziskavah je treba upoštevati, da je šlo za primerjavo gibalnih sposobnosti, in ne za primerjavo športne dejavnosti. Vemo pa, da so gibalne sposobnosti v veliki meri odvisne od športne dejavnosti, zato lahko sklepamo, da so športno dejavnejši otroci in mladostniki tudi gibalno sposobnejši.

Najpomembnejši razlog, da smo opravili pričujočo raziskavo, je bil, da študij, v katerih bi neposredno primerjali športno dejavnost otrok iz Slovenije in Srbije, konkretno iz Maribora in Novega Sada, še ni. Zato je bil glavni namen študije ugotoviti, koliko in na kakšen način so športno dejavni učenci iz Maribora in Novega Sada ter ali obstaja razlika v športni dejavnosti učencev iz omenjenih mest. Upoštevaje posebnosti okolja, predvsem materialnih pogojev za izvajanje športnih dejavnosti, iz katerega izhajajo otroci, vključeni v raziskavo, lahko pričakujemo, da ne bo posebnih razlik $\mathrm{v}$ nobeni izmed oblik športne dejavnosti med otroki iz Maribora in Novega Sada, in da so dečki aktivnejši od deklet.

\section{Metode}

\section{Vrorec}

Raziskavo smo izvedli na neslučajnostnem in priložnostnem vzorcu 202 učencev, ki so obiskovali 4., 5., 6. in 7. razred osnovnih šol, iz Maribora 102 učenca, iz Novega Sada pa 100 učencev, od tega je bilo 96 deklet, fantov pa 106. V raziskovalni vzorec je bilo zajetih 90,1 \% otrok, ki so živeli v mestu, drugi na podeželju.

\section{Postopki in organizacija zbiranja podatkov}

Za zbiranje podatkov smo uporabili anketni vprašalnik (Planinšec, Pišot in Fošnarič, 2006), s katerim smo dobili podatke o športni dejavnosti in preživljanju prostega časa otrok. Vprašalnik je bil anonimen, učenci pa so ga izpolnjevali v maternem jeziku. Tiskane anketne vprašalnike smo razdelili na šolah v Mariboru in v Novem Sadu, kjer smo izpolnjene vprašalnike tudi prevzeli. 


\section{Metode obdelave podatkov}

Podatki so bili obdelani s programom SPSS 21, pri tem smo uporabili deskriptivno statistiko, $\chi^{2}$-preizkus ter t-preizkus. Statistično značilnost razlik smo ugotavljali na ravni tveganja $\mathrm{p}<0,05$.

\section{Rezultati in razprava}

Iz tabele 1 je razvidno, da otroci iz Maribora $v$ povprečju obiskujejo športne interesne dejavnosti $v$ šoli slabi dve uri na teden, otroci iz Novega Sada pa nekaj manj kot eno uro na teden. Rezultat t-preizkusa je pokazal, da obstaja statistično pomembna razlika pri obiskovanju športnih interesnih dejavnosti med otroki iz Maribora in Novega Sada $(\mathrm{P}=0,006)$.

Tabela 1: Sodelovanje v interesnih športnih dejavnosti glede na kraj obiskovanja osnovne šole (ure na teden)

\begin{tabular}{|c|c|c|c|c|c|}
\hline \multirow{3}{*}{ Kraj obiskovanja šole } & \multicolumn{5}{|c|}{ Sodelovanje v športnih interesnih dejavnosti v OS } \\
\hline & \multirow{2}{*}{$\mathbf{N}$} & \multirow{2}{*}{ AS } & \multirow{2}{*}{ SO } & \multicolumn{2}{|c|}{ t-preizkus } \\
\hline & & & & $\mathbf{t}$ & $\mathrm{p}$ \\
\hline Maribor & 70 & 1,96 & 2,81 & & \\
\hline Novi Sad & 26 & 0,99 & 2,08 & 2,785 & 0,006 \\
\hline
\end{tabular}

Dobljeni rezultati kažejo, da je delež otrok, ki v šoli obiskuje športne interesne dejavnosti v Mariboru, bistveno večji kot v Novem Sadu. Ugotavljamo, da je pri nas dobra in kakovostna ponudba športnih interesnih programov, ki otroke pritegne. Otroci so kot interesno dejavnost $\mathrm{v}$ šoli navedli tudi sodelovanje $\mathrm{v}$ programu Zdrav življenjski slog (20,3\%), česar v Novem Sadu nimajo, kjer je največ anketirancev izbralo nogomet, sledita mu košarka in odbojka.

Rezultati v tabeli 2 kažejo, da otroci iz Maribora za organizirane športne dejavnosti porabijo več časa kot vrstniki iz Novega Sada, in sicer povprečno tri ure in pol na teden. V Novem Sadu pa obiskujejo organizirane športne dejavnosti povprečno dobri dve uri in pol na teden. Kljub temu da med otroki iz Maribora in Novega Sada ni statistično pomembne razlike $(\mathrm{p}=0,064)$, pa lahko rečemo, da obstaja tendenca statistično pomembne razlike. V Mariboru se otroci organizirano največ ukvarjajo z nogometom, gimnastiko in plesom, v Novem Sadu pa z borilnimi športi (karate, aikido, taekwondo, judo, boks), odbojko in nogometom. 
Tabela 2: Sodelovanje v organiziranih športnih dejavnostih glede na kraj obiskovanja osnovne šole (ure na teden)

\begin{tabular}{lcccccc}
\hline \multirow{2}{*}{ Kraj obiskovanja šole } & \multicolumn{6}{c}{ Sodelovanje v organiziranih športnih dejavnosti } \\
\cline { 2 - 4 } & $\mathbf{N}$ & AS & SO & \multicolumn{2}{c}{ t-preizkus } \\
\hline Maribor & 59 & 3,50 & 3,73 & & t & p \\
\hline Novi Sad & 53 & 2,60 & 3,10 & & 0,064 \\
\hline
\end{tabular}

Rezultati naše raziskave kažejo, da 55,4 \% otrok obiskuje organizirane športne dejavnosti, to je manj, kot ugotavljata Pišot in Zurc (2004). Po podatkih njune raziskave je bilo $\mathrm{v}$ organizirano obliko prostočasne gibalne/športne dejavnosti vključenih $70 \%$ učencev iz Slovenije. V drugi raziskavi pa avtorica Zurc (2011) navaja, da je 50,8 \% učencev v prostem času gibalno dejavnih v organizirani obliki, torej v društvih, pod strokovnim vodstvom, $\mathrm{v}$ športnih klubih, 49,2 \% učencev pa v neorganizirani obliki.

Tabela 3 prikazuje tedensko športno udejstvovanje z družinskimi člani. Rezultati kažejo, da se otroci v Mariboru športno več udejstvujejo z družinskimi člani, v povprečju kar dobre tri ure in pol na teden, v Novem Sadu pa v povprečju le slabo uro. Rezultati t-preizkusa so pokazali, da obstaja statistično pomembna razlika ( $\mathrm{p}=$ $0,00)$.

Tabela 3: Športno udejstvovanje z družinskimi člani glede na kraj obiskovanja osnovne šole (ure na teden)

\begin{tabular}{|c|c|c|c|c|c|}
\hline \multirow{3}{*}{ Kraj obiskovanja šole } & \multicolumn{5}{|c|}{ Športno udejstvovanje $\mathrm{z}$ družinskimi člani } \\
\hline & \multirow{2}{*}{$\mathbf{N}$} & \multirow{2}{*}{ AS } & \multirow{2}{*}{ SO } & \multicolumn{2}{|c|}{ t-preizkus } \\
\hline & & & & $\mathbf{t}$ & $\mathrm{p}$ \\
\hline Mari & 70 & 3,58 & 4,08 & \multirow{2}{*}{5,174} & \\
\hline Novi Sad & 19 & 0,96 & 3,01 & & 0,000 \\
\hline
\end{tabular}

Rezultati kažejo, da je v Novem Sadu le $19 \%$ otrok športno aktivnih skupaj z družinskimi člani, v Mariboru pa kar 68,6 \%. To, da se v Mariboru otroci bistveno več športno udejstvujejo z družinskimi člani kot v Novem Sadu, kaže na obstoj pomembnih razlik v življenjskem slogu družin. V Novem Sadu se v družinskem krogu največ ukvarjajo z nogometom in košarko, medtem ko je v Mariboru najbolj priljubljeno kolesarjenje, sledijo pa mu sprehod, pohodništvo ter nogomet.

Raziskava, ki so jo opravili Strel, Završnik, Pišot, Zurce in Kropej (2005), je pokazala, da je $35 \%$ otrok v 4. razredu športno dejavnih zaradi igre, zabave in sprostitve. Športna dejavnost s prijatelji narašča z otrokovo starostjo, saj je v tem 
otrokovem obdobju vedno manj športnega udejstvovanja z družinskimi člani. To je nekoliko izraziteje pri dečkih kot pri deklicah.

Rezultati v tabeli 4 kažejo, da se otroci iz Maribora povprečno ukvarjajo z neorganiziranimi športnimi dejavnostmi 3,82 ure na teden. Medtem se otroci iz Novega Sada ukvarjajo z neorganiziranimi športnimi dejavnostmi v povprečju dobri dve uri na teden. Rezultati t-preizkusa so pokazali obstoj statistično pomembne razlike med tedenskim udejstvovanjem $\mathrm{z}$ neorganiziranimi športnimi dejavnostmi $\mathrm{v}$ Mariboru in Novem Sadu.

Tabela 4: Sodelovanje v neorganiziranih športnih dejavnostih glede na kraj obiskovanja osnovne šole (ure na teden).

\begin{tabular}{lcccccc}
\hline \multirow{2}{*}{ Kraj obiskovanja šole } & \multicolumn{6}{c}{ Sodelovanje v neorganiziranih športnih dejavnostih } \\
\cline { 2 - 4 } \cline { 7 - 7 } & \multirow{2}{*}{ N } & \multirow{2}{*}{ AS } & SO & \multicolumn{3}{c}{ t-preizkus } \\
\hline Maribor & 74 & 3,82 & 4,388 & & t & P \\
\hline Novi Sad & 42 & 2,35 & 3,756 & & 0,011 \\
\hline
\end{tabular}

Med dejavnostmi, ki so jih navajali otroci iz Maribora, je na prvem mestu nogomet, sledijo pa mu kolesarjenje, tek, košarka, sprehod in športne igre. Tudi v Novem Sadu so najpogosteje navajali nogomet, sledijo pa košarka, odbojka in športne igre. Raziskava avtoric Živković, Marković in Stamenković (2013) je pokazala, da je med učenci v Beogradu najpopularnejši nogomet (12,74\%), sledijo odbojka (10,48 \%), košarka $(7,27 \%)$, folklorni plesi $(5,39 \%)$, tenis $(2,89 \%)$ ter plavanje $(2,19 \%)$. Gregorc in drugi (2013) pa so ugotovili, da so pri slovenskih 14-letnikih v prostem času najbolj popularne dejavnosti, kot so tek $(28,6 \%)$, odbojka $(19,6 \%)$, hitra hoja $(17,9 \%)$, nogomet $(16,1 \%)$, košarka in kolesarjenje $(14,3 \%)$.

Rezultati v tabeli 5 kažejo, da so si odgovori otrok glede na kraj bivanja pri sorojencih podobni, tukaj ni statistično pomembnih razlik. Bratje in sestre se povprečno s športom ukvarjajo redno, tako v Mariboru (52,0 \%) kot v Novem Sadu (60\%). Prijatelji se v največji meri s športom ukvarjajo redno, tako v Mariboru (70,6 $\%)$ kot v Novem Sadu (75,0 \%), sledijo jim prijatelji, ki se občasno ukvarjajo s športom, najmanj pa je takšnih, ki se s športom ne ukvarjajo. V tem primeru obstaja statistično pomembna razlika. Očetje anketirancev iz Maribora so najbolj športno aktivni (45,1\%), sledijo jim očetje, ki se s športom ukvarjajo občasno $(41,2 \%)$. V Novem Sadu pa je največ očetov, ki se s športom ukvarjajo občasno $(37,0 \%$ ), sledijo jim tisti, ki se s športom ne ukvarjajo (33,0\%). Tako kot pri očetih v Mariboru in Novem Sadu tudi pri materah obstaja statistično pomembna razlika. 
Matere se v največji meri s športom ukvarjajo občasno, tako v Mariboru (55,9\%) kot v Novem Sadu (39,0 \%). V Novem Sadu jim sledijo matere, ki se s športom ne ukvarjajo (36,0 \%), v Mariboru pa matere, ki so redno športno aktivne $(34,3 \%)$.

Tabela 5: Frekvenca (f) ter strukturni odstotek (f \%) športne dejavnosti družinskih članov ter najboljšega prijatelja glede na kraj obiskovanja šole

\begin{tabular}{|c|c|c|c|c|c|c|}
\hline \multirow{3}{*}{$\begin{array}{l}\text { Družinski } \\
\text { člani in } \\
\text { prijatelji }\end{array}$} & \multirow{3}{*}{$\begin{array}{l}\text { Pogostost } \\
\text { športne } \\
\text { dejavnosti }\end{array}$} & \multicolumn{5}{|c|}{ Kraj obiskovanja šole } \\
\hline & & \multicolumn{2}{|c|}{ Maribor } & \multicolumn{2}{|c|}{ Novi Sad } & \multirow{2}{*}{$\chi^{2}$-preizkus } \\
\hline & & f & f \% & f & f\% & \\
\hline \multirow{3}{*}{ Očetje } & redno & 46 & $45,1 \%$ & 30 & $30,0 \%$ & \multirow{3}{*}{$\begin{array}{c}\chi^{2}=11,596 \\
g=2 \\
P=0,003\end{array}$} \\
\hline & občasno & 42 & $41,2 \%$ & 37 & $37,0 \%$ & \\
\hline & nikoli & 14 & $13,7 \%$ & 33 & $33,0 \%$ & \\
\hline \multirow{3}{*}{ Matere } & redno & 35 & $34,3 \%$ & 25 & $25,0 \%$ & \multirow{3}{*}{$\begin{array}{c}\chi^{2}=20,649 \\
g=2 \\
P=0,000\end{array}$} \\
\hline & občasno & 57 & $55,9 \%$ & 39 & $39,0 \%$ & \\
\hline & nikoli & 10 & $9,8 \%$ & 36 & $36,0 \%$ & \\
\hline \multirow{3}{*}{$\begin{array}{l}\text { Bratje in } \\
\text { sestre }\end{array}$} & redno & 53 & $52,0 \%$ & 60 & $60,0 \%$ & \multirow{3}{*}{$\begin{array}{c}\chi^{2}=3,361 \\
g=2 \\
P=0,186\end{array}$} \\
\hline & občasno & 33 & $32,4 \%$ & 21 & $21,0 \%$ & \\
\hline & nikoli & 16 & $15,7 \%$ & 19 & $19,0 \%$ & \\
\hline \multirow{3}{*}{ Prijatelji } & redno & 72 & $70,6 \%$ & 75 & $75,0 \%$ & \multirow{3}{*}{$\begin{array}{c}\chi^{2}=7,495 \\
g=2 \\
P=0,024\end{array}$} \\
\hline & občasno & 27 & $26,5 \%$ & 15 & $15,0 \%$ & \\
\hline & nikoli & 3 & $2,9 \%$ & 10 & $10,0 \%$ & \\
\hline
\end{tabular}

Med najpomembnejše dejavnike okolja, ki pozitivno vplivajo na gibalno dejavnost otrok, sodi zagotovo družina. Po podatkih (Zurc 2011) se največ mater in očetov uvršča v skupino gibalno dejavnih večkrat tedensko, in sicer 37,9 \% očetov in 40,6 $\%$ mater, 23,5 \% mater ter 30,8 \% očetov v skupino vsakodnevno dejavnih, gibalno nedejavnih je 3,4 \% mater in 4,6 \% očetov. Moore, Lombardi, White, Campbell, Oliveria, Ellison (1991) so ugotavljali verjetnost med gibalno dejavnostjo otrok in gibalno dejavnost staršev. Če je oče dejaven, je verjetnost, da bodo otroci gibalno dejavni, večja za 3,5-krat, če je mati dejavna, je verjetnost večja za 2-krat, če sta oba starša dejavna, pa je verjetnost večja za 5,8 -krat.

\section{Sklep}

Glavni namen pričujoče raziskave je bil ugotoviti, koliko in na kakšen način so športno dejavni učenci iz Maribora in Novega Sada ter ali obstaja razlika v športni dejavnosti učencev iz omenjenih mest. Rezultati kažejo, da več kot polovica učencev $(52,5 \%)$ ne obiskuje športnih interesnih dejavnosti v osnovni šoli ter da učenci iz Maribora obiskujejo športne interesne dejavnosti v povprečju uro več na teden kot vrstniki iz Novega Sada. Ugotovili smo, da več kot polovica učencev $(55,4$ 
\%) obiskuje organizirane športne dejavnosti v prostem času, pri tem med otroki iz Maribora in Novega Sada ni statistično pomembnih razlik. Zanimivo je, da se, v celoti gledano, 55,9\% otrok v okviru družine športno ne udejstvuje. Otroci iz Maribora se športno udejstvujejo $z$ družinskimi člani v povprečju dobri dve uri in pol več na teden kot učenci iz Novega Sada. Z neorganiziranimi športnimi dejavnostmi se ukvarja 57,4 \% otrok, pri tem so učenci iz Maribora slabo uro in pol več aktivni kot učenci iz Novega Sada.

Zaključki, do katerih smo prišli, so na nek način skladni z dosedanjimi raziskavami (Planinšec, 2003; Pišot in Zurc, 2004; Strel, Završnik, Pišot, Zurc in Kropej, 2005; Kropej, 2007; Zurc, 2011; Đokić, 2014). Številne raziskave so namreč pokazale, da je večina otrok športno aktivnih in da je več takih, ki se s športno dejavnostjo ukvarjajo v organiziranih oblikah, takšna vadba je tudi najbolj kakovostna. Pravilno organizirana in strokovno usmerjena športna vadba je zagotovo najbolj koristna.

Tako kot je po eni strain spodbudno, da se veliko otrok ukvarja z različnimi oblikami športne dejavnosti, pa je po drugi strani zaskrbljujoče, da je še vedno prevelik delež otrok, ki niso športno aktivni. In ravno o teh bi morali več razmišljati, predvsem pa jih $\mathrm{v}$ šoli spodbujati $\mathrm{k}$ vključevanju $\mathrm{v}$ različne interesne športne dejavnosti. Kot so pokazale raziskave, je športna dejavnost zelo pomembna za otrokov razvoj, zato bi morali vzgojitelji, učitelji in starši še bolj poudarjati pomen gibanja ter tudi z lastnim zgledom otrokom približati zdrav življenjski slog. Učenci so v šolah vse bolj obremenjeni, zato bi bilo treba uvesti več gibalne aktivnosti, ki jim nudi razbremenitev. Otroke je treba spodbujati ter jim približati čim več dejavnosti, da lahko sami izberejo tiste, s katerimi se bodo z veseljem ukvarjali. Če jim že v zgodnjem otroštvu privzgojimo veselje in ljubezen do gibanja, obstaja večja verjetnost, da se bodo s tem ukvarjali tudi kasneje.

\section{Summary}

The most important rationale behind this research was the lack of studies directly comparing physical activity among students from Maribor and Novi Sad. The main aim of the study was to determine how physically active these students were and in what activities, and whether there was a difference in physical activity among students from Maribor and Novi Sad. The research was carried out on a random, informal sample of 202 students who attended the 4th, 5th, 6th and 7th grades of elementary school; 102 students were from Maribor and 100 were from Novi Sad, of which 96 were girls and 106 were boys. $90.1 \%$ of the students were from urban areas, while the others came from rural areas. For data collection, we used a survey 
questionnaire (Planinšec, Pišot and Fošnarič, 2006), which provided data about physical activities and leisure time for children. The questionnaire was anonymous and completed by students in their mother language. The data were processed with the SPSS 21 program, using descriptive statistics, the $\chi^{2}$-test and t-test. Statistical significance was set at an alpha level of 0.05 . The results show that there are significant differences between students from Maribor and those from Novi Sad in attending physical activities in school, physical activities with the family and in unorganized physical activity. There was no significant difference in attendance at organized physical activities. We can conclude that students from Maribor are more physically active than are students from Novi Sad. Furthermore, more than half the students $(52.5 \%)$ do not participate in physical activities in elementary school, and students from Maribor participate in physical activities for an hour a week more, on average, than their peers from Novi Sad. We found that more than half the students (55.4\%) attend organized physical activities in their leisure time, with no statistically significant differences between students from Maribor and those from Novi Sad. Interestingly, $55.9 \%$ of students do not participate in physical activities with their families. On average, students from Maribor engaged in physical activity with family members for two-and-a-half hours a week more than did students from Novi Sad. $57.4 \%$ of students are involved in unorganized physical activities, while students from Maribor are less than half an hour more active than their counterparts from Novi Sad. These results are consistent with other research (Planinšec, 2003; Pišot and Zurc, 2004; Kropej, 2007; Zurc, 2011; Đokić, 2014). Studies have shown that most children are physically active in organized activities. Properly organized and professionally focused physical exercise is the most beneficial. However, there are many students who are not physically active. We should encourage them to participate in various physical activities in school and in their leisure time. As research has shown, physical activity is very important for children's development and health; therefore, adults, especially teachers and parents, should emphasize the importance of physical activity and bring the healthy lifestyle closer to children. Students are becoming more and more burdened by schoolwork, so it is necessary for them to participate in a range of physical activities.

\section{Literatura}

Anastasovski, I. (2014). Organizovanje sportskih aktivnosti. Dostopno: http://savremenisport.com/teorija-sporta/sportski-menadzment/10/300/organizovanje-sportskih aktivnosti. (Pridobljeno 5. 10. 2018.)

Bouchard, C., Blair, S. N., Haskell, W. L. (2012). Physical activity and health. $2^{\text {nd }}$ Ed. Champaign: Human Kinetics.

Đokić, Z. (2014). Procena fizičke aktivnosti učenika uzrasta 11 godina. TIMS Acta, 8, 61-69. 
Gregorc, J., Karpljuk, D., Meško, M., Štihec, J., Videmšek, M., Videmšek, T. (2013). Športna dejavnost, učni uspeh in samopodoba štirinajstletnih učencev in učenk. Šport, 61 (3/4), str. $32-38$.

Hoffman, S. (2013). Introduction to Kinesiology - 4th Edition. Champaign: Human Kinetics.

How much do Europeans exercise? Dostopno: https://ec.europa.eu/eurostat/web/productseurostat-news/-/DDN-20170302-1 (Pridobljeno 20. 9. 2018.)

Jurak, G., Milanović, I., Radisavljević, J. S., Sorić, M., \& Kovač, M. (2015). Some indicators of fatness and motor fitness in Slovenian and Serbian children. Int. J. Morphol., 33 (2), 420-427.

Jurak, G., Radisavljević J. S., Milanović, I., Strel, J., Leskošek, B., Kovač, M. (2011). The comparison of physical fitness of 13-year-old students from Ljubljana and Belgrade. V Prskalo, I. (ur.), Novak, D. (ur.). Tjelesna i zdravstvena kultura u 21. stoljeću - kompetencije učenika = Physical education in the 21st century-pupils' competencies: zbornik radova = proceedings book. [Zagreb]: Hrvatski kineziološki savez. 2011, str. 219-229.

Kosi, M. (2011). Smernice za razuoj športa v Mestni občini Maribor (Raz̧iskovalno poročilo). Maribor: Mestna občina Maribor.

Kropej L, V. (2007). Povezanost gibalne/ športne aktivnosti otrok zį̧branimi dejavniki zdravega načina življenja. Doktorska disertacija. Univerza v Ljubljani, Fakulteta za šport, Ljubljana.

Landry, B.W., Driscoll, S.W. (2012). Physical Activity in Children and Adolescents. PM\&R Journal, 4 (11), 826-832.

McCormack, G. R., Giles-Corti, B., Timperio, A., Wood, G., Villanueva, K. (2011). A cross-sectional study of the individual, social, and built environmental correlates of pedometer-based physical activity among elementary school children. International Journal of Behavioral Nutrition and Physical Activity, 8 (30), 1-11.

Moore, L. L., Lombardi, D.A., White, M. J., Campbell, J. L., Oliveria, S. A., and Ellison, S. A. (1991). Influence of parent's physical activity levels on young children. Journal of Pediatrics, 118 (2), 215-219.

Nacionalni program športa v Republiki Sloveniji 2014-2023. (2014). Ljubljana: Ministrstvo za šolstvo in šport.

Norman, G. J., Adams, M. A., Kerr, J., Ryan, S., Frank, L. D., Roesch, S. C. (2010). A latent profile analysis of neighborhood recreation environments in relation to adolescent physical activity, sedentary time, and obesity. J Public Health Manag Pract. 16 (5), 411-419.

Panter, J., Guell, C., Prins, R., Ogilvie, D. (2017). Physical activity and the environment: conceptual review and framework for intervention research. International Journal of Behavioral Nutrition and Physical Activity. 14 (156), 1-13.

Pišot, R., Planinšec, J. (2005). Struktura motorike v zgodnjem otroštvu. Koper: Annales.

Pišot, R., Zurc, J. (2004). Gibalna/športna aktivnost pri učencih in učenkah drugega vzgojnoizobraževalnega obdobja osnovne šole. Pedagoška obzorja. 19 (1), 28-37.

Planinšec, J. (2003). Ugotavljanje gibalne dejavnosti mlajših otrok/Assessment of physical activity of young children. Zdravstveno varstvo, 1 (42), 58-65.

Planinšec, J., Pišot, R., Fošnarič, S. (2006). Gibalna aktivnost mlajših šolarjev v severovzhodni Sloveniji. Pedagoška obrorja, 21 (3/4), 3-14.

Pokrajinski sekretariata za sport i omadinu. Dostopno: https://www.sio.vojvodina.gov.rs/index.php/en/ (Pridobljeno 1. 10. 2018.)

Strel, J., Završnik, J., Pišot, R., Zurc, J. in Kropej, V. L. (2005). Ocena gibalne/športne aktivnosti ter zdravja otrok in mladostnikov. V J. Završnik in R. Pišot (Eds.), Gibalna/ sportna aktivnost qa 
zdravje otrok in mladostnikov, (str. 31-89). Koper: Založba Annales, Univerza na Primorskem, Znanstveno-raziskovalno središče, Inštitut za kineziološke raziskave.

Strong, William B., Malina, Robert M., Blimkie, Cameron J., Daniels, Stephen R., Dishman, Rodney K., Gutin, Bernard, Hergenroeder, Albert C., Must, Aviva, Niwon, Patricia A., Pivarnik, James M., Rowland, Thomas, Trost, Stewart, Trudeau, Francois. 2005. Evidence based physical activity for school-age youth. The Journal of Pediatrics, 146 (6), 732-737.

World Health Organization, (2013). Global Health Observatory: NCD mortality and morbidity. Dostopno: http://www.who.int/gho/ncd/mortality_morbidity/en/index.html (Pridobljeno 15. 9. 2018.)

Word Health Organization. (2017). How much of physical activity is recommended? Dostopno: http:/ /www.who.int/mediacentre/factsheets/fs385/en/ (Pridobljeno 15. 9. 2018.)

Zurc, J. (2011). Gibalna aktivnost slovenskih otrok. V Etiologija in patologija debelosti: zbornik prispevkov z recenzijo, (ur.) Avberšek Lužnik, I., Skela Savič, B., Skinder Savić, K., 162174. Jesenice: Visoka šola za zdravstveno nego Jesenice.

Živković, M., Marković, M., Stamenković, M. (2013). Angažovanost dece u sportu na teritoriji Beograda. Glasnik. Antropološkog drustua Srbije/Journal of the Antropological Society of Serbia, 1 (48), 129-136.

\section{Avtorja}

\section{Jasmina Jančič, mag. prof. raz. pouka}

Osnovna šola Sladki Vrh, Sladki Vrh 8a, 2214 Sladki Vrh, Slovenija, e-pošta: jasmina.jancic@ossladki-vrh.si

Elementary School Sladki Vrh, Sladki Vrh 8a, 2214 Sladki Vrh, Slovenija, e-mail: jasmina.jancic@ossladki-vrh.si

\section{Dr. Jurij Planinšec}

Redni profesor, Univerza v Mariboru, Pedagoška fakulteta Maribor, Koroška cesta 160, 2000 Maribor, Slovenija, e-pošta: jurij.planinsec@um.si

Full Professor, University of Maribor, Faculty of Education, Koroška cesta 160, 2000 Maribor, Slovenia, e-mail: jurij.planinsec@um.si 